\title{
SUDEP in the North American SUDEP Registry
}

The full spectrum of epilepsies

Chloe Verducci, BA, Fizza Hussain, MS, Elizabeth Donner, MD FRCP(C), Brian D. Moseley, MD, Jeffrey Buchhalter, MD, Dale Hesdorffer, PhD, Daniel Friedman, MD, MSc, and Orrin Devinsky, MD

Neurology ${ }^{\circledR}$ 2019;93:e227-e236. doi:10.1212/WNL.0000000000007778

\section{Abstract}

\section{Objective}

To obtain medical records, family interviews, and death-related reports of sudden unexpected death in epilepsy (SUDEP) cases to better understand SUDEP.

\section{Methods}

All cases referred to the North American SUDEP Registry (NASR) between October 2011 and June 2018 were reviewed; cause of death was determined by consensus review. Available medical records, death scene investigation reports, autopsy reports, and next-of-kin interviews were reviewed for all cases of SUDEP. Seizure type, EEG, MRI, and SUDEP classification were adjudicated by 2 epileptologists.

\section{Results}

There were 237 definite and probable cases of SUDEP among 530 NASR participants. SUDEP decedents had a median age of 26 (range 1-70) years at death, and 38\% were female. In 143 with sufficient information, $40 \%$ had generalized and $60 \%$ had focal epilepsy. SUDEP affected the full spectrum of epilepsies, from benign epilepsy with centrotemporal spikes $(n=3,1 \%)$ to intractable epileptic encephalopathies $(n=27,11 \%)$. Most (93\%) SUDEPs were unwitnessed; $70 \%$ occurred during apparent sleep; and $69 \%$ of patients were prone. Only $37 \%$ of cases of SUDEP took their last dose of antiseizure medications (ASMs). Reported lifetime generalized tonic-clonic seizures (GTCS) were $<10$ in $33 \%$ and 0 in $4 \%$.

\section{Conclusions}

NASR participants commonly have clinical features that have been previously been associated with SUDEP risk such as young adult age, ASM nonadherence, and frequent GTCS. However, a sizeable minority of SUDEP occurred in patients thought to be treatment responsive or to have benign epilepsies. These results emphasize the importance of SUDEP education across the spectrum of epilepsy severities. We aim to make NASR data and biospecimens available for researchers to advance SUDEP understanding and prevention.

\author{
Correspondence \\ Dr. Devinsky \\ od4@nyu.edu
}

RELATED ARTICLE

\section{Editorial}

SUDEP: Let's talk about it

Page 93

MORE ONLINE

\section{ค Podcast}

Dr. Halley Alexander talks with Dr. Orrin Devinsky about his paper on the full spectrum of epilepsies and the North American SUDEP Registry. NPub.org/bcfh4f

- CME Course

NPub.org/cmelist 


\section{Glossary}

ASM = antiseizure medication; CPR = cardiopulmonary resuscitation; GTCS = generalized tonic-clonic seizures; IQR = interquartile range; NASR = North American SUDEP Registry; NOK = next of kin; PNES = psychogenic nonepileptic seizures; PWE = people with epilepsy; SUDEP = sudden unexpected death in epilepsy; VNS = vagus nerve stimulator.

Sudden unexpected death in epilepsy (SUDEP) is a common cause of death among people with epilepsy (PWE), ${ }^{1}$ claiming $1 \%$ of patients' lives per decade, ${ }^{2}$ and is the second leading neurologic cause of lost potential life-years. ${ }^{3}$ When witnessed outside the hospital or recorded on video EEG, most SUDEPs follow $\geq 1$ generalized tonic-clonic seizures (GTCS) with death during the postictal state; however, some SUDEPs occur without a preceding electrographic or clinical seizure. ${ }^{4,5}$ Individual risk varies substantially and is highest in those with treatment-resistant epilepsy who have recent and frequent GTCS, especially during sleep. ${ }^{6}$ Other risk factors include lack of observation or monitoring in sleep and nonadherence to antiseizure medication (ASM). ${ }^{7}$ However, SUDEP can occur in patients with recent onset of epilepsy, well-controlled epilepsy, or benign epilepsies. ${ }^{8}$ Parallel cause of death in patients with provoked seizures (e.g., febrile seizures) is not diagnosed as epilepsy; thus, deaths are not SUDEP by definition. ${ }^{9,10}$

Knowledge about the epidemiology, risk factors, mechanisms, and prevention of SUDEP comes from population-based studies, medical examiner office case-control series, and clinical case-control series focused on specific subgroups (e.g., ASM trials, epilepsy surgery, vagus nerve stimulator [VNS], or responsive brain stimulation), epilepsy monitoring unit studies of seizures and postictal states, and animal models. ${ }^{11-14}$ These studies have greatly advanced our understanding about SUDEP, yet detailed clinical and pathologic studies remain limited to small samples, often derived from single subgroups (e.g., epilepsy surgery, children, pregnancy, epilepsy monitoring unit) or geographic regions. ${ }^{4,13,15-20}$ Larger series often focused on selected features (e.g., nocturnal, witnessed, prone position) or had limited access to detailed clinical data (e.g., medical examiner or VNS series). ${ }^{21-26}$

The North American SUDEP Registry (NASR) is a repository of medical records, comprehensive interviews with family members, and biospecimens (e.g., DNA, brain tissue) to aid investigations of SUDEP pathophysiology. Here, we report the comprehensive study of clinical characteristics and postmortem findings in a large consecutive series of SUDEPs.

\section{Methods}

\section{Participants}

Since October 2011, NASR has enrolled decedents with epilepsy, living controls with epilepsy, living first-degree relatives of presumed SUDEP cases, and control decedents with or without epilepsy. We reviewed all enrolled cases through June 2018. Family members of the decedents were referred to NASR from physicians, medical examiners or coroners, or advocacy groups (e.g., NIH Center for SUDEP Research, Epilepsy Foundation/SUDEP Institute, Dravet Syndrome Foundation, Dup15q Alliance, Danny Did Foundation) or were self-referred via an online search, recorded at the time of enrollment. If a first-degree relative indicated interest in NASR participation, saliva was collected; if the family member also had epilepsy, medical records were collected, and the case was enrolled as a living control and/or prospective brain donor, according to the individual's wishes.

\section{Standard protocol approvals, registrations, and patient consents}

All next of kin (NOK) provided written informed consent, and this study was approved by the New York University Langone Medical Center Institutional Review Board.

\section{Data collection}

A research assistant conducted a structured telephone interview that included social/familial history, medication history and adherence, seizure history and semiology, and circumstances of death (data available from Dryad, doi.org/ 10.5061/dryad.gn74mt3). For 2 cases for whom a language barrier limited verbal interview, NOK completed a questionnaire with assistance from the decedent's physician. Medical records included reports and original data for brain MRIs, EEGs or video EEGs, and ECGs. Seizure types, epilepsy etiology, MRI findings, and EEG results were abstracted with the use of the NIH Common Data Elements for epilepsy. ${ }^{27}$ A NASR neurologist or cardiologist adjudicated seizure types, epilepsy syndrome, and diagnostic test findings (EEG/video EEG, MRI, ECG) to confirm diagnosis.

To assess intellectual disability when formal testing was unavailable, we assumed normal intellectual function (IQ $>70$ ) if the individual was not diagnosed with intellectual disability and either $\geq 12$ years of education or full-time employment. Otherwise, intellectual status was considered unknown.

Sleep deprivation during the 24 hours before death was determined through NOK interview or death investigator records, including the decedent self-reporting being exhausted/very tired before terminal sleep, decedent went to sleep late or woke up early, or circadian rhythm disrupted from recent travel (e.g., 1 such case was noted "texting until 12:10 AM and woke up early for work"). Many cases lacked information on sleep status. 


\section{SUDEP adjudication}

We adjudicated cases using standard SUDEP criteria $^{1}$ to determine whether the death was SUDEP: a sudden, unexpected, witnessed or unwitnessed, nontraumatic, and nondrowning death, occurring in benign circumstances in a PWE, with or without evidence for a seizure, excluding documented status epilepticus (seizure duration $>30$ minutes or seizures without recovery in between). Definite SUDEP met all criteria with complete postmortem examination that did not reveal an alternative cause of death. Definite plus SUDEP met the definite criteria with a health condition or autopsy/ toxicologic finding that could have contributed to death. Probable SUDEP met the criteria for definite SUDEP without postmortem examination. Possible SUDEP had a competing cause of death. Two epileptologists (O.D. and D.F.) with SUDEP expertise independently reviewed all records to confirm epilepsy diagnosis and to determine SUDEP classification. In cases with disagreement, a third epileptologist with SUDEP expertise (E.D.) reviewed the case and achieved consensus. Non-SUDEP, near SUDEP, and possible SUDEP deaths were excluded from this analysis.

\section{Statistical analysis}

We report mean \pm SD or median and interquartile range (IQR) for continuous data. Statistics were performed with IBM SPSS Statistics, version 23 (IBM Corp, Armonk, NY). We assessed differences between SUDEP incidence by days of the week, months, or seasons using a $\chi^{2}$ goodness-of-fit test.

\section{Data availability}

Deidentified data will be available on request to any qualified researcher.

\section{Results}

NASR enrolled 331 epilepsy decedents, with 264 definite/ plus/probable SUDEPs: definite $(\mathrm{n}=135)$, definite plus $(\mathrm{n}=$ $25)$, probable $(n=77)$, possible $(n=16)$, or near $(n=11)$ cases. We enrolled 56 PWE who died of non-SUDEP causes, and 11 cases had insufficient information to categorize. Here, we report 237 cases of definite (57\%), definite plus (11\%), and probable SUDEPs (32\%). Interviews were conducted in 163 of $237(69 \%)$ cases. In the remainder, history was obtained exclusively from medical records and medical examiner reports.

One additional case was excluded because the individual had no lifetime history of seizures, but the death scene was typical of SUDEP (found in morning dead after period of sleep deprivation, "tangled in comforter on the floor" with arms close to chest with hand in fisted position). Neuropathology revealed focal cortical dysplasia.

\section{Demographics}

The median age of the 237 cases of SUDEP was 26 years (range 1-70 years) (figure $1 \mathrm{~A})$, and $38 \%(\mathrm{n}=89)$ were female. The average age for definite SUDEP cases was 25 years
Figure 1 Distribution of ages, most recent seizures before death, and lifetime seizure frequencies

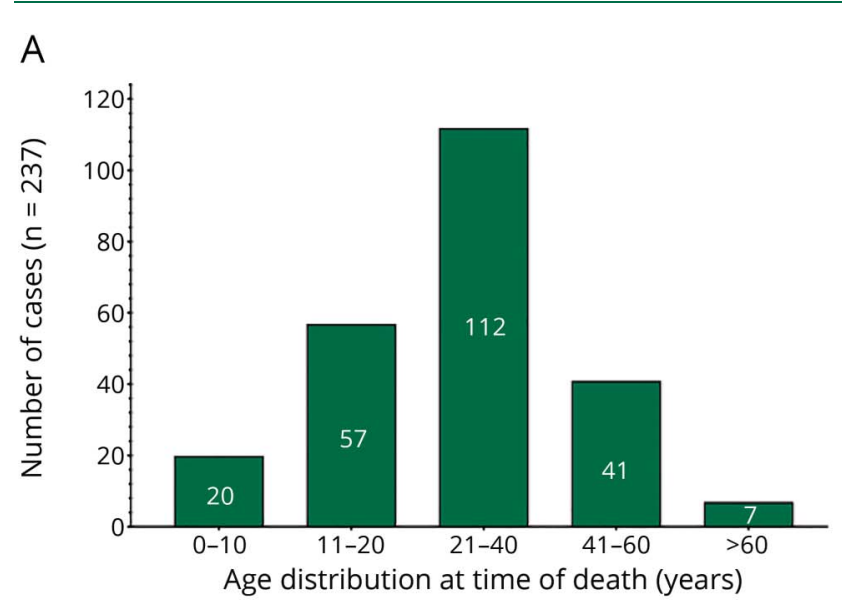

B

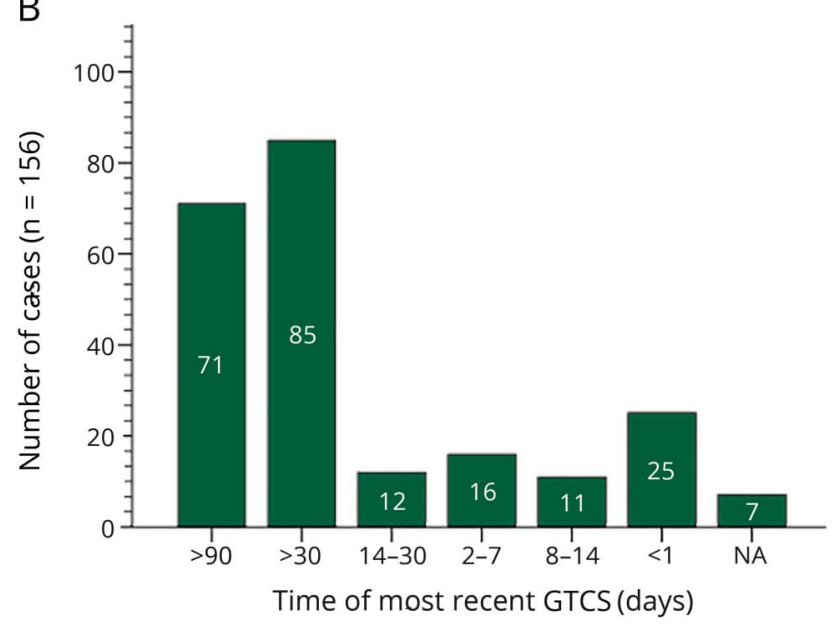

C

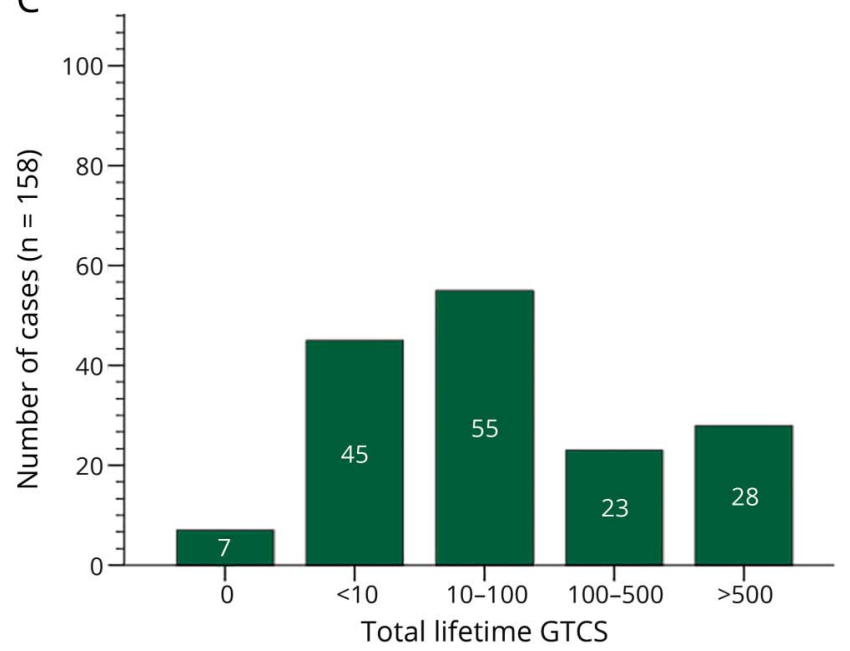

(A) Age distribution at the time of death, (B) time of most recent generalized tonic-clonic seizures (GTCS), and (C) total lifetime GTCS.

(SD 13 years); for definite SUDEP plus, 40 years (SD 14 years); and for probable SUDEP, 24 years (SD 15 years). Ethnicities (reported by NOK interview or listed in medical records) were as follows: white 79\% $(\mathrm{n}=188)$, black $9 \%(\mathrm{n}=$ $22)$, and Hispanic $11 \%(\mathrm{n}=25)$. Other ethnicities (1\%) 
included South Asian or East Asian American and Native Hawaiian or Pacific Islander. Among 173 adults (age >16 years), education history was available in 140 cases: $26 \%$ (37 of 140) had a bachelor's degree or higher; 62\% (87 of 140) had some college education; and 88\% (123 of 140) had a high school diploma, general equivalency diploma, or greater.

Contact was initiated to NASR by the decedent's NOK through medical examiners $(31 \%, \mathrm{n}=49)$, patient/family support group $(18 \%, \mathrm{n}=29)$, the decedent's physician $(21 \%$, $\mathrm{n}=33)$, or web search $(17 \%, \mathrm{n}=26)$. The rest found NASR through other families or physicians $(7 \%, \mathrm{n}=11)$ or other sources $(n=9)$, and contact was unspecified in 80 cases. Only $16 \%(n=39)$ of NOK had heard about SUDEP before their relatives' death.

\section{Circumstances of death}

Death was witnessed in 7\% (16 of 237) of SUDEPs, with a seizure observed immediately preceding death in 10 of 16 (63\%) witnessed cases. Of the 6 witnessed cases without terminal seizure, 4 had difficulty breathing immediately before death, and 1 was in a typical postictal state. Thirteen (81\%) cases received cardiopulmonary resuscitation (CPR) either by a CPR-trained bystander or directly by EMS personnel. Of 16 witnessed SUDEPs, 7 were presumed asleep and 9 were awake (e.g., exiting the shower, speaking with friends in their room, or sitting on the porch drinking beer).

Many unwitnessed SUDEPs were administered CPR on discovery. Although time between terminal seizure or death and EMS response cannot be determined, it appears that most cases of unwitnessed SUDEP were administered CPR after the decedent had already been discovered dead (table 1).

Only 37\% (66 of 180) had reportedly taken their last prescribed ASM dose before death, and 23 cases were not prescribed ASMs.

Table 1 Circumstances of death $(n=237)$

\begin{tabular}{llll}
\hline Circumstance of death & $\mathbf{n}$ & $\mathbf{N}$ & \% \\
\hline Took last ASM dose? & 66 & 180 & 37 \\
\hline Asleep at time of death & 118 & 168 & 70 \\
\hline Known recent illness & 30 & 175 & 17 \\
\hline Room sharing during sleep & 57 & 161 & 35 \\
\hline CPR performed & 108 & 212 & 51 \\
\hline Sleep deprived & 24 & 157 & 15 \\
\hline Full autopsy performed & 155 & 237 & 65 \\
\hline Found in prone position & 128 & 186 & 69 \\
\hline Evidence of preceding seizure & 123 & 167 & 74
\end{tabular}

Abbreviations: ASM = antiseizure medication; $\mathrm{CPR}=$ cardiopulmonary resuscitation.
Of the 157 decedents with narratives surrounding the circumstances of death, $15 \%$ (24 of 157 ) were reported to be sleep deprived at the time of death. The 80 cases (36\%) without interviews lacked information to determine sleep status before death.

A full autopsy was performed in 65\% (155) of cases (table 1). Of these 155 cases with autopsy, 142 (92\%) listed a seizurerelated cause or contributing cause of death. The other 13 were attributed to cardiac (9), respiratory (3), or hepatic (1) causes; 6 of these cases were classified as definite plus SUDEP. Brain tissue (whole brain, portions, or slides) was donated for 120 decedents; DNA samples were donated for 144 decedents. Medical examiner death scene investigation reports and autopsy/ toxicology reports were obtained for 155 cases (table 2). Full neuropathology examinations were performed by NASR for

Table 2 Major autopsy findings $(n=237)$

\begin{tabular}{lcc}
\hline Death report finding & $\mathrm{n}$ & $\%$ \\
\hline BMI $(\mathrm{n}=\mathbf{1 6 6}), \mathbf{k g} / \mathrm{m}^{2}$ & & \\
\hline$<18$ & 17 & 10 \\
\hline $\mathbf{1 8 . 1 - 2 5}$ & 68 & 41 \\
\hline $\mathbf{2 5 . 1}-\mathbf{3 0}$ & 44 & 27 \\
\hline$>30.1$ & 37 & 22
\end{tabular}

Evidence of preceding seizure $(n=237)$

\begin{tabular}{lll}
\hline None & 44 & 19 \\
\hline Incontinence & 31 & 13 \\
\hline Tongue bite & 31 & 13 \\
\hline Blood on pillow & 24 & 10 \\
\hline Bedding askew & 6 & 3
\end{tabular}

Cardiac autopsy findings $(n=145)$

\begin{tabular}{lll}
\hline Atherosclerosis & 31 & 21 \\
\hline Stenosis (coronary artery) & 17 & 12 \\
\hline Hypertrophy & 14 & 10 \\
\hline Pulmonary findings $(\mathbf{n}=\mathbf{1 4 2})$ & & \\
\hline Congestion & 78 & 55 \\
\hline Edema & 57 & 40 \\
\hline Neuropathologic findings $(\mathbf{n}=\mathbf{1 3 0})$ & & \\
\hline Sclerosis & 10 & 8 \\
\hline Gliosis & 8 & 6 \\
\hline Focal cortical dysplasia & 7 & 5 \\
\hline Hemorrhage & 7 & 5 \\
\hline Congestion/edema & 6 & 5 \\
\hline
\end{tabular}

Abbreviation: $\mathrm{BMI}=$ body mass index. 
28 decedents; 25 (89\%) demonstrated epilepsy-related changes, most commonly gliosis (43\%), focal dysgenesis of the dentate gyrus (29\%), and focal cortical dysplasias type I/IIA (21\%/18\%). In 136 cases, the median brain weight was 1,424 g (IQR $1,269-1,542 \mathrm{~g})$. The mean weights of SUDEP brains for both adult women $>16$ years of age $(1,324 \mathrm{~g}$ [SD $139 \mathrm{~g}])$ and adult men $>16$ years of age $(1,543 \mathrm{~g}$ [SD $201 \mathrm{~g}])$ in our cohort were slightly higher than reported in aggregated autopsy reports of normal brain weights for women $(1,287 \mathrm{~g})$ and men $(1,418 \mathrm{~g}){ }^{28}$ Lung pathology revealed pulmonary edema in $40 \%$ (57 of 142) and pulmonary congestion in 55\% (78 of 142); congestion and edema concurred in 30\% (42) of cases. Genetic analysis of NASR biospecimens for relevant neurologic, cardiac, and respiratory findings is currently being conducted.

\section{Seizure history}

Among SUDEPs, the median epilepsy duration was 13 years (available for 198 of 237, IQR 5-23 years). The median age at onset was 10 years (198 of 237, IQR 3-17 years). For the 143 cases with sufficient data to make electroclinical diagnoses, $40 \%$ (57) had generalized epilepsy, 60\% (86) had focal epilepsy, and 10\% (15) had both generalized and focal epilepsies. The remaining $40 \%$ (94 of 237) were unclassified due to lack of data, ambiguity, or discordant data (table 3 ).

The interval between last seizure and SUDEP is plotted in figure 1B. Seven cases had no known lifetime GTCS (5 had focal unaware seizures and 2 had focal seizures with preserved awareness). Estimated lifetime number of GTCS is

Table 3 Seizure histories in cases of SUDEP with sufficient information to adjudicate (143 of 237)

\begin{tabular}{|c|c|c|c|}
\hline Seizure history & n & $\mathbf{N}$ & $\%$ \\
\hline Generalized & 57 & 143 & 40 \\
\hline Tonic-clonic & 46 & 143 & 32 \\
\hline Focal & 86 & 143 & 60 \\
\hline Focal to bilateral & 67 & 143 & 47 \\
\hline Preserved awareness & 20 & 143 & 14 \\
\hline Impaired awareness & 59 & 143 & 41 \\
\hline Unclassified & 94 & 237 & 40 \\
\hline Both & 15 & 143 & 10 \\
\hline Seizure-free at time of death ${ }^{a}$ & 27 & 182 & 15 \\
\hline \multirow[t]{2}{*}{ Psychogenic seizures } & 6 & 166 & 4 \\
\hline & Median & & IQR \\
\hline Duration, y & 12 & & $5-23$ \\
\hline Age at onset, y & 10 & & $3-17$ \\
\hline
\end{tabular}

Abbreviations: IQR = interquartile range; SUDEP = sudden unexpected death in epilepsy.

a Seizure-free at time of death includes only cases who have experienced a period of seizure freedom in the full year before death, excluding possible terminal seizure. summarized in figure 1C. Of the 28 cases whose family members reported $>500$ lifetime GTCS, 4 had LennoxGastaut syndrome, 7 had Dup15q chromosomal abnormality, 6 had Dravet syndrome, and 1 had both Lennox-Gastaut syndrome and Dup15q.

Data on seizure frequency before death were obtained from interviews and medical records and represent best estimates for many patients. In the month before death, $54 \%$ had no GTCS. During the 3 months before death in the 153 patients with data available, $42 \%$ had no GTCS and $14 \%$ had 1 GTCS. In 182 cases with sufficient data in the year before death, 15\% were seizure-free.

Among the 27 patients who were seizure-free during the year before death, 7 had idiopathic generalized epilepsy (4 with GTCS), 9 had focal epilepsy (5 with GTCS), and 11 had unknown epilepsy classification. The average age at death for cases seizure-free in the year before death was 29 years, and $63 \%$ were male, similar to the overall cohort. Among these 27 cases, $82 \%$ were taking ASMs, and $8 \%$ had undergone epilepsy surgery or VNS implantation.

Psychogenic nonepileptic seizures (PNES) with comorbid epilepsy were diagnosed in 6 of 166 (4\%) SUDEPs; 4 were male. For the 6 cases of PNES, the median age at epilepsy diagnosis for the group was 4.5 years (IQR 0.9-10.25 years), and the median age at PNES diagnosis for the group was 25 years $(n=6)$. The median age at death for the PNES group was 22 years (IQR 12.75-30.5 years), lower than for the SUDEP cases without PNES: median age at epilepsy diagnosis was 10 years (IQR 3.0-17.0 years) and at death was 26 years (IQR $18.0-47.0$ years).

\section{Epilepsy treatment history}

Among the 203 cases with sufficient data, $89 \%(\mathrm{n}=180)$ were prescribed ASMs, and 23 (11\%) were never prescribed an ASM. During interviews, NOK recalled ASM adherence status in 170 cases, even when specific ASMs could not be named; of these, 66\% (113) were adherent and 34\% were nonadherent (frequently forgot ASMs, took subtherapeutic doses to reduce side effects, or intentionally skipped or stopped ASM). Medication adherence was unknown in 44 cases.

Data on specific ASMs at the time of death were available in 180 of 237 cases, compiled from postmortem testing, medical records, and recall during the interview. The most frequent ASMs were levetiracetam $(39 \%, \mathrm{n}=71)$, lamotrigine $(26 \%$, $\mathrm{n}=47)$, valproate $(15 \%, \mathrm{n}=27)$, topiramate $(13 \%, \mathrm{n}=24)$, and oxcarbazepine $(12 \%, \mathrm{n}=22)$. For these 180 cases, 56 were taking 1 ASM, 62 were taking 2 ASMs, and 62 were taking $\geq 3$ ASM ( 2 cases were taking 6 concurrent ASMs). Of the 140 cases with toxicology reports, no antiepileptic drugs were detected in $40(29 \%)$, including patients who were nonadherent (34) and those who were never prescribed antiepileptic drugs (6). 
Of 57 patients who were nonadherent with ASMs, information about psychiatric history was obtained in 47: 70\% had no psychiatric conditions listed and 30\% had anxiety disorder $(\mathrm{n}=8)$, bipolar disorder $(\mathrm{n}=2)$ schizophrenia $(\mathrm{n}=$ $2)$, adjustment disorder $(n=1)$, or extreme anger $(n=1)$. Of these nonadherent cases, 26 were active alcohol users, and 19 were currently using recreational drugs. The mean age at death for these cases was 28 years, similar to the group as a whole.

Epilepsy surgery was performed on 18\% (42 of 237) of cases, including temporal lobectomies $(n=19)$, extratemporal lobe resections $(n=3)$, corpus callosotomy $(n=6)$, and lesionectomy $(\mathrm{n}=8)$ (arteriovenous malformation $[\mathrm{n}=2]$, tumor $[\mathrm{n}=2]$, ganglioma $[\mathrm{n}=1]$, or subdural and epidural hematoma $[\mathrm{n}=1]$, and 1 foreign body excision). Neurostimulating devices were implanted in 32 of 237 (14\%): 31 had a VNS, and 1 had a deep brain stimulator.

Dietary therapy for epilepsy was attempted by 25 of 237 $(11 \%)$ : ketogenic diet $(n=20)$, modified Atkins diet $(n=4)$, low glycemic diet $(n=2)$, or other seizure diets $(n=3)$, with some attempting $>1$ therapeutic diet in their lifetime.

Medical and psychiatric comorbid conditions are summarized in figure 2.

\section{Epilepsy syndromes and etiologies}

Epilepsy syndromes included Dravet syndrome in 5\% ( $\mathrm{n}=$ $13)$, juvenile myoclonic epilepsy in $4 \%(n=9)$, Dup $15 q$ chromosomal abnormality in $4 \%(n=9)$, febrile seizure plus syndrome in $3 \%(n=7)$, Lennox-Gastaut syndrome in $3 \%$ $(n=5)$, and benign epilepsy with centrotemporal spikes in $1 \%$ $(n=3) .^{8}$ The causes of epilepsy for SUDEP cases were often unknown. Among 150 cases with sufficient data to classify etiology, 43\% (64) had epilepsy of unknown cause. The rest included genetic/presumed genetic or epileptic encephalopathies $(n=33)$, traumatic brain injury $(n=11)$, malformations of cortical development $(n=7)$, or a viral, bacterial, or parasitic infection $(n=4)$.

MRI, EEG, ECG findings are listed in table 4.

\section{Other common risk factors}

Around the time of death, 15 had alcohol use disorder; of these, 4 were drinking alcohol the night they died, with 3 of 4 binge drinking that night. In most cases, data were not available on alcohol consumption on the day before death. Toxicology reports from 140 decedents found alcohol in 6\%, although this may be an overestimate due to postmortem decomposition artifact and may be an underestimate of the role of alcohol withdrawal, which may be associated with nondetectable ethanol levels.

History of recreational drug use was assessed in 196 cases: $12 \%$ used illegal drugs near the time of death, and $7 \%$ used them previously. These drugs included marijuana $(n=33)$, amphetamines $(n=4)$, cocaine $(n=2)$, and heroin $(n=2)$. No lifetime use of illicit drugs was reported in $81 \%$. Among medical examiner-referred cases $(n=49), 20 \%$ had used illegal drugs and $12 \%$ used illicit drugs at the time of death. Toxicology reports in 140 cases found illegal drugs (10\%), including marijuana $(\mathrm{n}=9)$, amphetamines $(\mathrm{n}=4)$, and opiates $(\mathrm{n}=1)$.

One hundred seventy-six cases shared the bed while sleeping, most frequently with spouses or parents. Among the 118 cases with data, $86 \%(\mathrm{n}=102)$ had an estimated IQ >70, while $14 \%$ $(\mathrm{n}=16)$ had an IQ $<70$.

There was no relationship between SUDEP and day of the week $\left(\chi^{2}=2.013, p<0.05\right)(\mathrm{n}=230)$, month of year $\left(\chi^{2}=\right.$

Figure 2 Comorbid conditions reported in cases of sudden unexpected death in epilepsy $(n=237)$

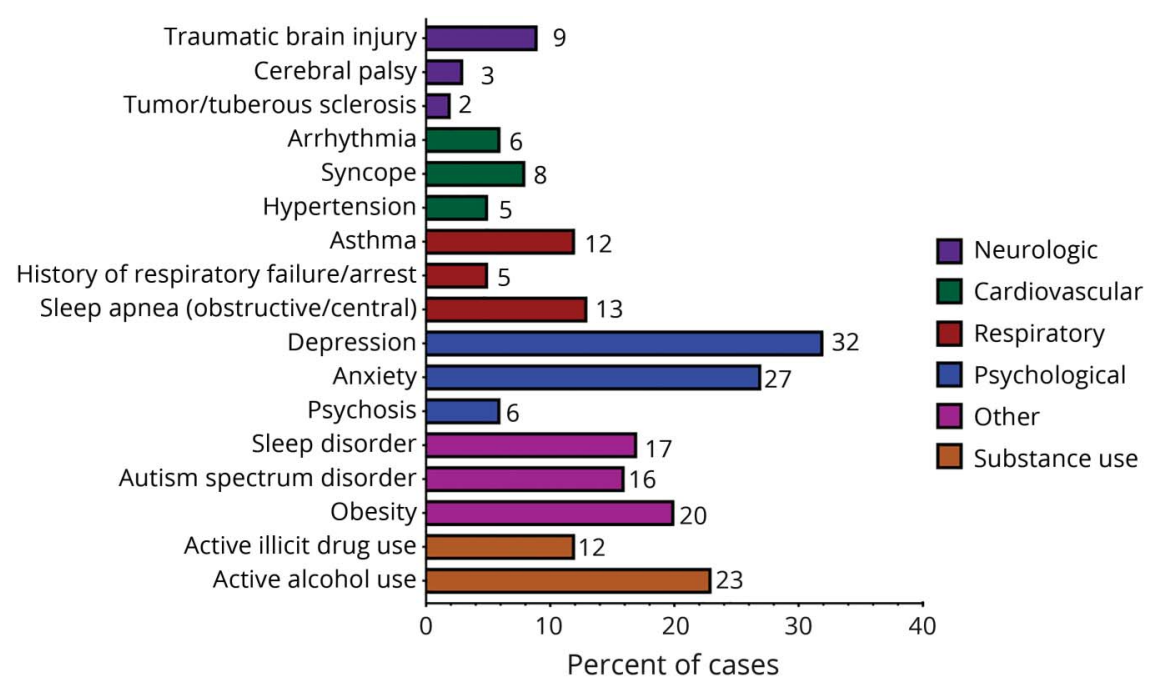


Table 4 EEG, MRI, and ECG findings

\begin{tabular}{|c|c|c|}
\hline Finding & $\mathbf{n}$ & $\%$ \\
\hline \multicolumn{3}{|l|}{ EEG $(n=129)$} \\
\hline Normal & 22 & 17 \\
\hline Focal slowing & $15 \mathrm{~L} / 14 \mathrm{R}$ & $12 \mathrm{~L} / 11 \mathrm{R}$ \\
\hline Focal dysfunction/dysrhythmia & $13 \mathrm{~L} / 22 \mathrm{R}$ & $10 \mathrm{~L} / 17 \mathrm{R}$ \\
\hline Generalized slowing & 40 & 31 \\
\hline Epileptiform activity & 36 & 28 \\
\hline Generalized dysfunction/dysrhythmia & 32 & 25 \\
\hline Seizure recorded & 45 & 35 \\
\hline \multicolumn{3}{|l|}{ MRI $(n=106)$} \\
\hline Normal & 60 & 57 \\
\hline Postoperative/resection changes & 14 & 13 \\
\hline Atrophy & 10 & 9 \\
\hline Sclerosis (any) & 9 & 8 \\
\hline Mesial temporal sclerosis & 9 & 8 \\
\hline Cyst & 5 & 5 \\
\hline Dysplasia & 3 & 3 \\
\hline Tumor/lesion & 2 & 2 \\
\hline \multicolumn{3}{|l|}{ ECG $(n=47)$} \\
\hline Normal & 18 & 38 \\
\hline Tachycardia & 8 & 17 \\
\hline Arrhythmia (+LQTS) & 7 & 15 \\
\hline Atrial enlargement & 4 & 9 \\
\hline
\end{tabular}

Abbreviation: LQTS = long-QT syndrome.

$2.82, p<0.05)(\mathrm{n}=230)$, or season $\left(\chi^{2}=0.5165, p<0.05\right)(\mathrm{n}$ $=230)$.

\section{Discussion}

We report 237 cases of definite and probable SUDEP, the largest series with extensive ascertainment and adjudication of medical records, death scene investigations, and autopsy reports to confirm epilepsy diagnosis and to accurately identify seizure types and epilepsy syndromes; EEG, MRI, and ECG findings; and SUDEP classification. Our data expand what is currently considered the typical case or spectrum of SUDEP. Although SUDEP is most common in the intractable epilepsies, our findings establish that SUDEP affects the full spectrum of epilepsies, from benign epilepsy with centrotemporal spikes to epileptic encephalopathies and failed resective surgeries. The distribution of generalized and focal epilepsy paralleled their frequency in the general epilepsy population: $40 \%$ had generalized seizures, $60 \%$ had focal seizures, and $10 \%$ had both. ${ }^{29,30}$ Finally, lack of ASMs was common: $11 \%$ were not prescribed ASMs, with only $37 \%$ of those prescribed ASMs reported to have taken their last dose before death. This suggests that a single missed dose of ASM may, in some patients and circumstances, increase SUDEP risk.

Because SUDEP can occur in patients with epilepsy who are seizure-free, have never had tonic-clonic seizure, or were diagnosed with a benign epilepsy syndrome, clinicians should discuss SUDEP with all PWE for 2 reasons. First, some reassurance can be given to relieve anxiety for those at low risk (e.g., focal aware or absence seizures only). Second and most important, patients and families must understand the critical — and potentially lifesaving-importance of seizure control. Many SUDEPs could likely be prevented by ASM adherence and lifestyle factors (sleep hygiene, limited/no alcohol), and many lives are likely saved by patients and families pursuing aggressive seizure management and possibly by monitoring to detect seizures and provide prompt first aid.

Our series paralleled prior studies, with the peak age distribution in young adults, frequent occurrence in apparent sleep (70\%), death in the prone position (69\%), low rate of witnessed death (7\%), and evidence of a preceding seizure in most cases (74\%). ${ }^{21,31}$ However, $27 \%$ of our sample was $<16$ years of age, which is 2 -fold more than the combined $13 \%$ of SUDEPs in the 0- to 20-year age ranges reported in a pooled analysis from high-quality population-based studies of SUDEP incidence across all age groups. ${ }^{2}$ Our findings, although partly reflecting referral bias, accord with recent population-based cohorts showing that pediatric SUDEPs are more common than suspected. ${ }^{2,32}$ SUDEPs in older children and young adults (11-40 years of age, $71 \%)$, unwitnessed or unaccompanied death (93\%), and found in the prone position (69\%) were prevalent in our study, all of which are previously documented SUDEP risk factors. ${ }^{9}$

Among the 16 (7\%) witnessed SUDEPs, 10 had seizures immediately preceding death. Of the 6 other cases without preceding seizure, 4 had difficulty breathing around the terminal event. This provides further anecdotal evidence for proposed pathophysiologic mechanisms of SUDEP of seizures followed by acute respiratory distress or arrest. ${ }^{33} \mathrm{We}$ need additional studies of cases of witnessed near SUDEP in the epilepsy monitoring unit with cardiopulmonary monitoring devices. Access to rapidly responsive emergency medical providers was key in resuscitating cases for $>1$ hour (i.e., near SUDEP) $)^{34}$ and, in many cases, preventing death.

Among unwitnessed cases of SUDEP with known sleep state at the time of death (153), death was more likely to occur during sleep (73\%) than while awake (27\%). This contrasts to cases of witnessed SUDEP (16), which were more frequently awake (55\%) than asleep. Witnessed seizures are more likely to receive rapid, potentially lifesaving first aid, which would reduce the frequency of witnessed SUDEPs. Sleep state may 
be conducive to SUDEP independently of a witness or first aid. For some, a perfect storm of sleep state, altered reduced sympathetic activity, serotonin circadian cycling, and more prolonged postictal generalized EEG suppression leading to cerebral shutdown may combine to impair autonomic function, arousal, and respiration, making SUDEP more likely with seizures during sleep. ${ }^{35,36}$

As with prior studies, we found that recent history and high frequency of GTCS are common among SUDEP decedents. The high number of lifetime GTCS in this cohort partly reflects patients with epileptic encephalopathies for which very frequent GTCS are retrospectively reported by parents. ${ }^{37}$

While the majority of decedents in this study had a high lifetime GTCS burden, many reported good seizure control before death. Paradoxically, most SUDEPs in our cohort occurred in patients who are traditionally considered at low SUDEP risk. Our findings also highlight an important issue regarding GTCS frequency and SUDEP. While frequent GTCS are known to increase the relative risk of SUDEP, most PWE have relatively few GTCS. Therefore, in absolute numbers, SUDEP occurs more frequently in people who have relatively milder forms of epilepsy. However, these findings are consistent in that they highlight different aspects of SUDEP: high GTCS frequency increases SUDEP risk in a small group, but the low-risk group is much larger and accounts for most SUDEPs. ${ }^{12}$ Long periods of seizure freedom could potentially increase SUDEP risk if seizures that occur after a long period of seizure freedom are more dangerous due to a relative lack of tolerance or adaptive recovery responses. One mother feared long periods of seizure freedom in her daughter because the GTCS that followed would often be worse than her typical convulsions. Relatively seizure-free patients must remain vigilant to mitigate risk because ASM nonadherence or lifestyle lapses could prove fatal.

Seven (3\%) cases never had a GTCS before SUDEP. Thus, SUDEP risk is not limited to patients with frequent or uncontrolled GTCS. SUDEP should be discussed with all patients and families, regardless of their seizure type, severity, or frequency. ${ }^{10}$

We studied other SUDEP risk factors, including intellectual disability, alcohol or illicit drug use, and medication nonadherence. The IQ range of our cohort was similar to that of epilepsy populations; $14 \%$ had intellectual disability. ${ }^{19}$ Alcohol use was not frequent in our cohort; $23 \%$ were current alcohol users, and $64 \%$ never used alcohol, similar to prior studies. ${ }^{7}$ However, our data reflect only available history, and many SUDEP cases were referred by medical examiners and had limited history. Toxicology findings may bias referrals and influence adjudication because deaths with illicit drug use findings are more likely adjudicated as not SUDEP or possible SUDEP (i.e., overdose is a competing cause of death).

At least $15 \%$ of decedents were sleep deprived before death. This conservative figure includes only cases for whom this information was explicitly stated by NOK or confirmed through investigative reports. Because sleep deprivation is a seizure provocation factor, it may be a risk factor for SUDEP. ${ }^{38}$ We found no relationship of SUDEP to day of the week, month, or season of the year, similar to prior studies. ${ }^{39}$

Only $16 \%$ of NOK were aware of SUDEP before their loved one's death, similar to our earlier report ${ }^{40} ; 74 \%$ of this group were glad it was discussed. Among those who had not learned of SUDEP, 78\% wish they had been told beforehand. Doctors routinely fail to educate patients and families about SUDEP and ways to reduce risk despite families' interest in this information and its potential to save the family member's life. ${ }^{41}$

Our cohort had higher comorbidity rates than the general epilepsy population, including depressive (32\% compared to $23 \%$ reported in a meta-analysis of psychiatric disorders among $\mathrm{PWE}^{42}$ ) and anxiety disorders $(27 \%$ compared to $11 \%-25 \%$ in the same reference study ${ }^{42}$ ), autism spectrum disorder $(16 \%)$, and apnea (13\%). While the high rates of autism spectrum disorder and possibly apnea may reflect our biased recruiting of patients with Dup15q syndrome and Dravet syndrome, high rates of depressive and anxiety disorders exceed that of the general epilepsy population and are biased down by the epileptic encephalopathy populations, in which these psychiatric diagnoses were infrequent. In patients with treatment-resistant epilepsy who underwent epilepsy surgery and had prospective, systematic assessments, moderate to severe depression and anxiety were identified in $22.1 \%$ and $24.7 \%$, respectively. ${ }^{43}$ In contrast, our data were limited by lack of available medical records, and we lacked either prospective or systematic psychiatric assessments. The prevalence of psychiatric comorbid conditions was likely higher than we identified. A large population-based study in Sweden found that PWE have an $\approx 11$-fold increase in the odds ratio of death during a 55-year follow-up period compared to the general population. ${ }^{44}$ Of the $15.8 \%$ who died of external causes (e.g., suicide, accident, drowning, assault), psychiatric comorbid conditions, especially depression and substance misuse, occurred in $75 \%$.

Our study has multiple limitations. Self-referral or advocacy group referrals likely biased our sample toward higher socioeconomic, white, and younger cases. Our series comprised cases from various referral sources, with only $31 \%$ coming from a population base (i.e., San Diego County). In contrast, in the population-based recruitment through medical examiner office referrals, only 17 of 49 cases had finished high school, and $12 \%$ were unemployed. Furthermore, $47 \%$ of those enrolled through a medical examiner were black or Hispanic/Latino vs $13 \%$ of our cohort referred through other sources. The families of most decedents had high medical literacy or access to healthcare providers to learn of NASR. This highlights the nonrandomness of our missing data, often skewed toward collecting higher-quality medical records from patients of a higher socioeconomic status who had more access to specialty care. Interviews were more frequently 
conducted in these cases than in medical examiner referrals, for which NOK often waived consent to be recontacted or were lost to follow-up. In the $31 \%$ of our cases without interviews, information relied on investigative reports and medical records, which often have limited data. Thus, data including last witnessed GTCS and medication compliance were inconsistent, limiting the generalizability of conclusions about SUDEP mechanisms. We hypothesize that ASM nonadherence, sleep deprivation, alcohol withdrawal, and comorbid psychiatric disorders may have a greater role in SUDEP than we could identify.

Data were also limited by recall bias, inherent in retrospective interviews. Although we sought family interviews shortly after enrollment, many were postponed due to grieving or difficulty recontacting. This time interval was even longer among cases enrolled months or years after death. Details on circumstances of dying, medication compliance, and seizure phenotype in many cases were ambiguous. Many parents of adult children lacked accurate information about their child's seizure frequency, history of substance abuse, or other details about daily life. Our inability to classify epilepsy syndrome as focal or generalized in $40 \%$ of cases reflects inclusion of medical examiner cases who often lacked routine neurologic or other medical care. In other cases, despite care at epilepsy centers, semiologic features (e.g., tonic-clonic seizures without aura) or normal/ nonspecific EEG findings did not permit classification.

The lack of a population-based cohort or representative control cohort limits our ability to compare and determine possible risk factors between cases of SUDEP and living cases of epilepsy or non-SUDEP epilepsy deaths. NASR hopes to recruit representative epilepsy and nonepilepsy control cases to compare to cases of SUDEP.

We will make NASR data available to physicians and researchers to collaborate or perform their own historical, genetic, and pathologic analyses. We hope to leverage NASR data and biospecimens to accelerate the understanding the risk factors and mechanisms underlying SUDEP and to advance preventive strategies and interventions. For more information, please see sudepregistry.org.

\section{Study funding}

Funded by Finding a Cure for Epilepsy and Seizures, Lundbeck, and American Epilepsy Society.

\section{Disclosure}

C. Verducci and F. Hussain report no disclosures relevant to the manuscript. E. Donner receives consulting fees from Eisai and UCB. She also receives research grants from Ontario Brain Institute and Canadian Institutes of Health Research. B. Moseley has served on advisory boards for UCB Pharma, Eisai, and Validus Pharmaceuticals. He also serves on speakers bureaus for UCB Pharma, LivaNova, and Eisai. He receives research support from LivaNova, Sunovion, and the NASR at New York University. J. Buchhalter is on the executive committee of the NASR. He also receives salary support for consulting and clinical trial-related activities performed on behalf of The Epilepsy Study Consortium, a nonprofit organization. He has received consulting fees for services provided to Insys, Inc and Zogenix. D.C. Hesdorffer is on the committee of the NASR at New York University. She has received research support from the Epilepsy Study Consortium, a nonprofit organization, and Patient-Centered Outcomes Research Institute Patient-Powered Research Network for the Rare Epilepsy Network. She is an associate editor of Epilepsia and a reviewer of Epilepsy and Behavior. She has received travel reimbursement related to research, meetings, or presentations of results at scientific meetings. D. Friedman is on the executive committee of the NASR. He also receives salary support for consulting and clinical trial-related activities performed on behalf of The Epilepsy Study Consortium, a nonprofit organization. Dr. Friedman receives no personal income for these activities. New York University receives a fixed amount from the Epilepsy Study Consortium towards Dr. Friedman's salary. Within the past year, The Epilepsy Study Consortium received payments for research services performed by Dr. Friedman from Adamas, Biogen, CuroNZ, Engage Pharmaceuticals, Eisai, GW Pharmaceuticals, Pfizer, Takeda, and Zynerba. He has also served as a paid consultant for Eisai and Penumbra. He has received honorarium from Neuropace, Inc. He receives research support from Empatica, Epitel, UCB, Inc, and Neuropace. He holds ownership interests in Neuroview Technology. O. Devinsky serves on the medical or scientific advisory board and receives compensation from Privateer Holdings/Tilray, Egg Rock/Papa \& Barkley, Receptor Life Sciences, Empatica, Tevard, Engage, Rettco, and Pairnomix/Q-state. He has received consulting fees from Zogenix and GW Pharmaceuticals. He is the principal investigator (uncompensated) for the NASR and the Sudden Unexplained Death in Childhood Registry and Research Collaborative. He receives grant support from the National Institute of Neurological Disorders and Stroke, National Institute of Mental Health, Department of Defense, and Centers for Disease Control and Prevention. Go to Neurology.org/N for full disclosures.

\section{Publication history}

Received by Neurology December 6, 2018. Accepted in final form March 15, 2019.

Appendix Authors

\begin{tabular}{|c|c|c|c|}
\hline Name & Location & Role & Contribution \\
\hline $\begin{array}{l}\text { Chloe } \\
\text { Verducci, } \\
\text { BA }\end{array}$ & $\begin{array}{l}\text { Comprehensive } \\
\text { Epilepsy Center, } \\
\text { New York } \\
\text { University School of } \\
\text { Medicine, NY }\end{array}$ & Author & $\begin{array}{l}\text { Drafting and } \\
\text { revision, data } \\
\text { collection, } \\
\text { statistical analysis }\end{array}$ \\
\hline $\begin{array}{l}\text { Fizza } \\
\text { Hussain, MS }\end{array}$ & $\begin{array}{l}\text { Comprehensive } \\
\text { Epilepsy Center, } \\
\text { New York } \\
\text { University School of } \\
\text { Medicine, NY }\end{array}$ & Author & $\begin{array}{l}\text { Drafting and } \\
\text { revision, data } \\
\text { collection }\end{array}$ \\
\hline
\end{tabular}


Appendix (continued)

\begin{tabular}{|c|c|c|c|}
\hline Name & Location & Role & Contribution \\
\hline $\begin{array}{l}\text { Elizabeth } \\
\text { Donner, } \\
\text { MD, FRCP }\end{array}$ & $\begin{array}{l}\text { Division of } \\
\text { Neurology, The } \\
\text { Hospital for Sick } \\
\text { Children, Toronto, } \\
\text { Ontario, Canada }\end{array}$ & Author & $\begin{array}{l}\text { Drafting and } \\
\text { revision }\end{array}$ \\
\hline $\begin{array}{l}\text { Brian D. } \\
\text { Moseley, } \\
\text { MD }\end{array}$ & $\begin{array}{l}\text { Epilepsy Center, } \\
\text { Gardner } \\
\text { Neuroscience } \\
\text { Institute, University } \\
\text { of Cincinnati } \\
\text { Health, OH }\end{array}$ & Author & $\begin{array}{l}\text { Drafting and } \\
\text { revision }\end{array}$ \\
\hline $\begin{array}{l}\text { Jeffrey } \\
\text { Buchhalter, } \\
\text { MD }\end{array}$ & $\begin{array}{l}\text { University of } \\
\text { Calgary, Alberta, } \\
\text { Canada }\end{array}$ & Author & $\begin{array}{l}\text { Drafting and } \\
\text { revision }\end{array}$ \\
\hline $\begin{array}{l}\text { Dale } \\
\text { Hesdorffer, } \\
\text { PhD }\end{array}$ & $\begin{array}{l}\text { Gertrude H. } \\
\text { Sergievsky Center, } \\
\text { Division of } \\
\text { Epidemiology, } \\
\text { Columbia } \\
\text { University Medical } \\
\text { Center, New York, } \\
\text { NY }\end{array}$ & Author & $\begin{array}{l}\text { Drafting and } \\
\text { revision }\end{array}$ \\
\hline $\begin{array}{l}\text { Daniel } \\
\text { Friedman, } \\
\text { MD, MSc }\end{array}$ & $\begin{array}{l}\text { Comprehensive } \\
\text { Epilepsy Center, } \\
\text { New York } \\
\text { University School of } \\
\text { Medicine, }\end{array}$ & Author & $\begin{array}{l}\text { Design and } \\
\text { conceptualized } \\
\text { study, drafting and } \\
\text { revision, data } \\
\text { collection, } \\
\text { statistical analysis }\end{array}$ \\
\hline $\begin{array}{l}\text { Orrin } \\
\text { Devinsky, } \\
\text { MD }\end{array}$ & $\begin{array}{l}\text { Comprehensive } \\
\text { Epilepsy Center } \\
\text { New York } \\
\text { University School of } \\
\text { Medicine, NY }\end{array}$ & $\begin{array}{l}\text { Author, } \\
\text { principal } \\
\text { investigator }\end{array}$ & $\begin{array}{l}\text { Design and } \\
\text { conceptualized } \\
\text { study, data } \\
\text { collection, drafting } \\
\text { and revision }\end{array}$ \\
\hline
\end{tabular}

\section{References}

1. Nashef L, So E, Ryvlin P, Tomson T. Unifying the definitions of sudden unexpected death in epilepsy. Epilepsia 2011;53:227-233.

2. Sveinsson O, Andersson T, Carlsson S, Tomson T. The incidence of SUDEP: a nationwide population-based cohort study. Neurology 2017;89:170-177.

3. Thurman DJ, Hesdorffer DC, French JA. Sudden unexpected death in epilepsy: assessing the public health burden. Epilepsia 2014;55:1479-1485.

4. Donner E, Smith C, Snead O. Sudden unexplained death in children with epilepsy. Neurology 2011;57:430-434.

5. Lhatoo SD, Nei M, Raghavan M, et al. Nonseizure SUDEP: sudden unexpected death in epilepsy without preceding epileptic seizures. Epilepsia 2016;57:1161-1168.

6. Tomson T, Nashef L, Ryvlin P. Sudden unexpected death in epilepsy: current knowledge and future directions. Lancet Neurol 2008;7:1021-1031.

7. Hesdorffer DC, Tomson T, Benn E, et al. Combined analysis of risk factors for SUDEP. Epilepsia 2011;52:1150-1159.

8. Doumlele K, Friedman D, Buchhalter J, Donner EJ, Louik J, Devinsky O. Sudden unexpected death in epilepsy among patients with benign childhood epilepsy with centrotemporal spikes. JAMA Neurol 2017;74:645-649.

9. Devinsky O, Hesdorffer DC, Thurman DJ, Lhatoo S, Richerson G. Sudden unexpected death in epilepsy: epidemiology, mechanisms, and prevention. Lancet Neurol 2016;15:1075-1088.

10. Hesdorffer DC, Crandall LA, Friedman D, Devinsky O. Sudden unexplained death in childhood: a comparison of cases with and without a febrile seizure history. Epilepsia 2015;56:1294-1300.

11. Tomson T, Hirsch LJ, Friedman D, et al. Sudden unexpected death in epilepsy in lamotrigine randomized-control trials. Epilepsia 2013;54:135-140.

12. DeGiorgio CM, Markovic D, Mazumder R, Moseley BD. Ranking the leading risk factors for sudden unexpected death in epilepsy. Front Neurol 2017;8:473-476.

13. Ryvlin P, Nashef L, Lhatoo SD, et al. Incidence and mechanisms of cardiorespiratory arrests in epilepsy monitoring units (MORTEMUS): a retrospective study. Lancet Neurol 2013;12:966-977.
14. Pasani A, Colugnati D, Scorza A, et al. Furthering our understanding of SUDEP: the role of animal models. Expert Rev Neurother 2016;16:561-572.

15. Sperling MR, Feldman H, Kinman J, Liporace JD, O'Connor MJ. Seizure control and mortality in epilepsy. Ann Neurol 1999;46:45-50.

16. Cooper MS, Mcintosh A, Crompton DE, et al. Mortality in Dravet syndrome. Epilepsy Res 2016;128:43-47.

17. Wandschneider B, Koepp M, Scott C, et al. Structural imaging biomarkers of sudden unexpected death in epilepsy. Brain 2015;138:2907-2919.

18. Lhatoo SD, Faulkner HJ, Dembny K, Trippick K, Johnson C, Bird JM. An electroclinical case-control study of sudden unexpected death in epilepsy. Ann Neurol 2010; 68:787-796.

19. Walczak TS, Leppik IE, D'Amelio M, et al. Incidence and risk factors in sudden unexpected death in epilepsy: a prospective cohort study. Neurology 2001;56: 519-525.

20. Edey S, Moran N, Nashef L. SUDEP and epilepsy-related mortality in pregnancy. Epilepsia 2014;55:e72-4.

21. Lamberts RJ, Thijs RD, Laffan A, Langan Y, Sander JW. Sudden unexpected death in epilepsy: people with nocturnal seizures may be at highest risk. Epilepsia 2012;53: 253-257.

22. Liebenthal JA, Wu S, Rose S, Ebersole JS, Tao JX. Association of prone position with sudden unexpected death in epilepsy. Neurology 2015;84:703-709.

23. Ryvlin P, So EL, Gordon CM, et al. Long-term surveillance of SUDEP in drug resistant epilepsy patients treated with VNS therapy. Epilepsia 2018;59:562-572.

24. Zhuo L, Zhang Y, Zielke HR, et al. Sudden unexpected death in epilepsy: evaluation of forensic autopsy cases. Forensic Sci Int 2012;223:171-175.

25. Sveinsson O, Andersson T, Carlsson S, Tomson T. Circumstances of SUDEP: a nationwide population-based case series. Epilepsia 2018;59:1074-1082.

26. Davis G, McGwin GJ. Comparison of heart mass in seizure patients dying of sudden unexpected death in epilepsy to sudden death due to some other cause. Am J Forensic Med Pathol 2004;25:23-28.

27. Loring DW, Lowenstein DH, Barbaro NM, et al. Common data elements in epilepsy research: development and implementation of the NINDS Epilepsy CDE Project. Epilepsia 2011;52:1186-1191.

28. Dekaban AS, Sadowsky D. Changes in brain weights during the span of human life: relation of brain weights to body heights and body weights. Ann Neurol 1978;4: 345-356.

29. Ablah E, Hesdorffer DC, Liu Y, et al. Prevalence of epilepsy in rural Kansas. Epilepsy Res 2014;108:792-801.

30. Manford M, Hart Y, Sander JS, Shorvon S. The National General Practice Study of Epilepsy: the syndromic classification of the International League Against Epilepsy applied to epilepsy in a general population. Arch Neurol 1992;49:801-808.

31. Harden C, Tomson T, Gloss D, et al. Practice guideline summary: sudden unexpected death in epilepsy incidence rates and risk factors: report of the Guideline Development, Dissemination, and Implementation Subcommittee of the American Academy of Neurology and the American Epilepsy Society. Epilepsy Currents 2017; 88:180-187.

32. Keller AE, Whitney R, Li SA, Pollanen MS, Donner EJ. Incidence of sudden unexpected death in epilepsy in children is similar to adults. Neurology 2018;91 e107-e111.

33. Goldman AM. Mechanisms of sudden unexplained death in epilepsy. Curr Opin Neurol 2015;28:166-174

34. Devinsky O, Bundock E, Hesdorffer D, et al. Resolving ambiguities in SUDEP classification. Epilepsia 2018;59:1220-1233.

35. Ali A, Wu S, Issa NP, et al. Association of sleep with sudden unexpected death in epilepsy. Epilepsy Behav 2017;76:1-6.

36. Bozorgi A, Lhatoo SD. Seizures, cerebral shutdown, and SUDEP. Epilepsy Curr 2013, 13:236-240.

37. Conant K, Finucane B, Cleary N, et al. A survey of seizures and current treatments in 15q duplication syndrome. Epilepsia 2014;55:396-402.

38. Scorza F, Duncan S, Cavalheiro E, Scorza C, Tufik S, Andersen M. Sleep tight, wake up bright: should sleep deprivation be included as a potential risk factor for SUDEP? Epilepsy Behav 2014;33:75-76.

39. Bell GS, Peacock JL, Sander JW. Seasonality as a risk factor for sudden unexpected death in epilepsy: a study in a large cohort. Epilepsia 2010;51:773-776.

40. Louik J, Doumlele K, Hussain F, et al. Experiences with premorbid SUDEP discussion among participants in the North American SUDEP Registry (NASR). Epilepsy Behav 2017;70:131-134

41. Friedman D, Donner EJ, Stephens D, Wright C, Devinsky O. Sudden unexpected death in epilepsy: knowledge and experience among U.S. and Canadian neurologists. Epilepsy Behav 2014;35:13-18.

42. Kwon OY, Park SP. Depression and anxiety in people with epilepsy. J Clin Neurol 2014;10:175-188.

43. Devinsky O, Barr WB, Vickrey BG, et al. Changes in depression and anxiety after resective surgery for epilepsy. Neurology 2005;65:1744-1749.

44. Fazel S, Wolf A, Langstrom N, Newton C, Lichtenstein P. Premature mortality in epilepsy and the role of psychiatric comorbidity: a total population study. The Lancet 2013;382:16-22 


\section{Neurology}

\section{SUDEP in the North American SUDEP Registry: The full spectrum of epilepsies}

Chloe Verducci, Fizza Hussain, Elizabeth Donner, et al.

Neurology 2019;93;e227-e236 Published Online before print June 19, 2019

DOI 10.1212/WNL.0000000000007778

This information is current as of June 19, 2019

\section{Updated Information \& Services}

References

Citations

Subspecialty Collections

Permissions \& Licensing

Reprints including high resolution figures, can be found at: http://n.neurology.org/content/93/3/e227.full

This article cites 44 articles, 4 of which you can access for free at: http://n.neurology.org/content/93/3/e227.full\#ref-list-1

This article has been cited by 10 HighWire-hosted articles: http://n.neurology.org/content/93/3/e227.full\#\#otherarticles

This article, along with others on similar topics, appears in the following collection(s):

All Epilepsy/Seizures

http://n.neurology.org/cgi/collection/all_epilepsy_seizures

Information about reproducing this article in parts (figures,tables) or in its entirety can be found online at:

http://www.neurology.org/about/about_the_journal\#permissions

Information about ordering reprints can be found online:

http://n.neurology.org/subscribers/advertise

Neurology ${ }^{\circledR}$ is the official journal of the American Academy of Neurology. Published continuously since 1951, it is now a weekly with 48 issues per year. Copyright Copyright (C) 2019 The Author(s). Published by Wolters Kluwer Health, Inc. on behalf of the American Academy of Neurology.. All rights reserved. Print ISSN: 0028-3878. Online ISSN: 1526-632X.

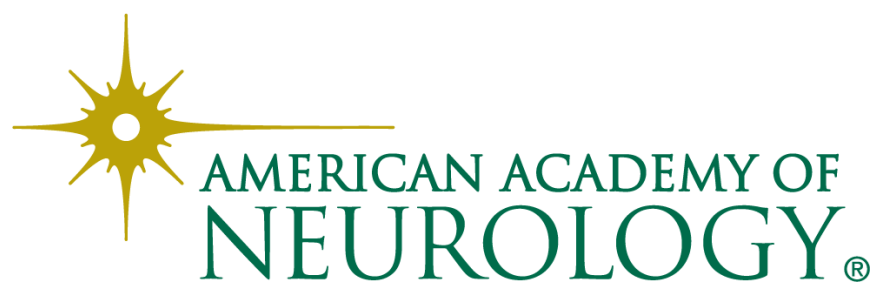

